\title{
The Link Between the Ecology of the Prokaryotic Rare Biosphere and Its Biotechnological Potential
}

\author{
Francisco Pascoal ${ }^{1,2}$, Catarina Magalhães ${ }^{2,3,4,5 \dagger}$ and Rodrigo Costa ${ }^{1,6,7,8 * t}$ \\ ${ }^{1}$ Department of Bioengineering, Institute for Bioengineering and Biosciences (iBB), Instituto Superior Técnico, University \\ of Lisbon, Lisbon, Portugal, ${ }^{2}$ Interdisciplinary Centre of Marine and Environmental Research (CIIMAR/CIMAR), University \\ of Porto, Porto, Portugal, ${ }^{3}$ Faculty of Sciences, University of Porto, Porto, Portugal, ${ }^{4}$ School of Science \& Engineering, \\ University of Waikato, Hamilton, New Zealand, ${ }^{5}$ Ocean Frontier Institute, Dalhousie University, Halitax, NS, Canada, ${ }^{6}$ Centre \\ of Marine Sciences (CCMAR), University of Algarve, Faro, Portugal, ${ }^{7}$ U.S. Department of Energy Joint Genome Institute, \\ Berkeley, CA, United States, ${ }^{8}$ Environmental Genomics and Systems Biology Division, Lawrence Berkeley National \\ Laboratory, Berkeley, CA, United States
}

OPEN ACCESS

Edited by:

Edgardo Donati,

National University of La Plata,

Argentina

Reviewed by:

Giovanna Cristina Varese, University of Turin, Italy

Shimshon Belkin,

The Hebrew University of

Jerusalem, Israel

Ramona Marasco,

King Abdullah University of Science and Technology, Saudi Arabia

*Correspondence: Rodrigo Costa rodrigoscosta@tecnico.ulisboa.pt

†These authors have contributed equally to this work

Specialty section: This article was submitted to Microbiotechnology,

a section of the journal Frontiers in Microbiology

Received: 17 May 2019 Accepted: 31 January 2020 Published: 19 February 2020

Citation:

Pascoal F, Magalhães $C$ and Costa R (2020) The Link Between the Ecology of the Prokaryotic Rare Biosphere and Its Biotechnological Potential. Front. Microbiol. 11:231. doi: 10.3389/fmicb.2020.00231
Current research on the prokaryotic low abundance taxa, the prokaryotic rare biosphere, is growing, leading to a greater understanding of the mechanisms underlying organismal rarity and its relevance in ecology. From this emerging knowledge it is possible to envision innovative approaches in biotechnology applicable to several sectors. Bioremediation and bioprospecting are two of the most promising areas where such approaches could find feasible implementation, involving possible new solutions to the decontamination of polluted sites and to the discovery of novel gene variants and pathways based on the attributes of rare microbial communities. Bioremediation can be improved through the realization that diverse rare species can grow abundant and degrade different pollutants or possibly transfer useful genes. Further, most of the prokaryotic diversity found in virtually all environments belongs in the rare biosphere and remains uncultivatable, suggesting great bioprospecting potential within this vast and understudied genetic pool. This Mini Review argues that knowledge of the ecophysiology of rare prokaryotes can aid the development of future, efficient biotechnology-based processes, products and services. However, this promise may only be fulfilled through improvements in (and optimal blending of) advanced microbial culturing and physiology, metagenomics, genome annotation and editing, and synthetic biology, to name a few areas of relevance. In the future, it will be important to understand how activity profiles relate with abundance, as some rare taxa can remain rare and increase activity, whereas other taxa can grow abundant. The metabolic mechanisms behind those patterns can be useful in designing biotechnological processes.

Keywords: bioremediation, bioprospection, microbial dark matter, microbial ecology, biotechnology

\section{INTRODUCTION}

Low abundance microbial taxa are usually referred to as members of the "Rare Biosphere"(Sogin et al., 2006), a relatively recent, but important concept to understand microbial ecology from a fundamental perspective (Jia et al., 2018). The microbial rare biosphere encompasses a large diversity of prokaryotes and microeukaryotes, both with a recognized role in ecosystem functioning (Logares et al., 2015; Jousset et al., 2017). This Mini Review covers, unless stated otherwise, the recent and larger body of work that unequivocally links the rare status of prokaryotic populations 
with genotypic traits and activities of potential use in bioremediation and bioprospection. We direct the reader to the reviews by Weisse (2014) and Logares et al. (2015) and the reports by Ziegler et al. (2018) and Murdock and Juniper (2019) for current insights into the ecology of rare microeukaryotes.

In general, the microbial rare biosphere may act as a "seed bank" (Pedrós-Alió, 2006) where cells are dormant or metabolically inactive (Neufeld et al., 2008; Jones and Lennon, 2010), thereby hinting at why they exist in such low numbers. If cells within this seed bank are viable, by changing conditions low abundance microorganisms can become abundant (Shade et al., 2014). Another possibility is that cells in low-abundance populations are metabolically active (Campbell et al., 2011; Hugoni et al., 2013; Logares et al., 2013), but do not grow to become abundant in the environment (Galand et al., 2009; Kirchman et al., 2010; Gobet et al., 2012; Debroas et al., 2015; Liu et al., 2015) likely due to intrinsic metabolic limitations (Pedrós-Alió, 2012). Low-abundance microorganisms can also act as "keystone species", meaning they have a disproportional effect on specific functions relative to their abundance (Caron and Countway, 2009; Pester et al., 2010; Hausmann et al., 2019). Finally, they can simply be a consequence of random dispersal and exist only transiently (Sogin et al., 2006; Fuhrman, 2009; Jousset et al., 2017). All the above-mentioned observations form the basis for the existence of different "types of rarity" across space and/or time (Vergin et al., 2013; Lynch and Neufeld, 2015; Jia et al., 2018). When DNA-based methods are used to describe the rare microbial biosphere, a considerable proportion of the observed diversity may be representative of dying or dead cells (Pedrós-Alió, 2012).

Independently of the mechanisms explaining rarity and its spatial-temporal behavior, it is now widely accepted that, both within prokaryotes and single-celled eukaryotes ("protists"), the microbial rare biosphere constitutes an important "genomic reservoir" or "pool of diversity" (Youssef et al., 2010; Bowen et al., 2012; Logares et al., 2014, 2015; Lynch and Neufeld, 2015; Fuentes et al., 2016) that is likely to play fundamental roles in ecosystem functioning. Thus, this community of lowabundance species would contain many different genes that could be used for a variety of functions. Besides, the rare biosphere may also perform the same functions of the abundant biosphere, conferring "functional redundancy" to the entire community (Szabó et al., 2007; Coveley et al., 2015). Particularly within prokaryotes, the metabolic potential encrypted in this genomic reservoir is considered to be mostly unknown and therefore a source of "genetic novelty"(Elshahed et al., 2008; Zhang et al., 2009) - which is often correlated with the concept of "microbial dark matter" due to the usual lack of cultivability of rare prokaryotes (Lynch and Neufeld, 2015; Ramond et al., 2015), therefore representing an important component of phylogenetic diversity (Lloyd et al., 2018). Notwithstanding, the rare biosphere also includes a wealth of known and culturable taxa (Shade et al., 2012; Hardoim et al., 2014; Karimi et al., 2019) that can be straightforwardly examined in biotechnology-driven research. Several recent studies suggest that the prokaryotic rare biosphere can mediate the response of natural ecosystems to environmental perturbations and pollution (Table 1). The sections below highlight metabolic, genotypic and physiological traits of reportedly low-abundance prokaryotes which illustrate possible links with biotechnology.

\section{THE ECOPHYSIOLOGY OF THE PROKARYOTIC RARE BIOSPHERE}

Currently, the consensus is that natural prokaryotic communities can respond to perturbations and environmental shifts through the rare biosphere (Figure 1) because of its high diversity (Jousset et al., 2017). Such a response can be explained from the perspective of the seed bank theory (Pedrós-Alió, 2006). For example, rare bacteria were found to become abundant when exposed to salinity and Dissolved Organic Carbon (DOC) gradients in seawater, while the overall functions of the community were maintained (Sjöstedt et al., 2012; Table 1). A similar study tested the effects of changing salinity and temperature on sulfide-rich spring communities, also confirming that rare prokaryotes can become abundant in response to both slow and fast perturbations (Coveley et al., 2015). Here, unique rare phylotypes were most responsive, suggesting that additional phylogenetic diversity equips the community with the ability to cope with diverse environmental changes (Table $\mathbf{1}$ ).

In the environment, the prokaryotic rare biosphere response is thought to be composed of at least two main mechanisms: clonal amplification, i.e., conditionally rare taxa (CRT) that become abundant with changing conditions; and/or horizontal gene transfer (HGT) of functional traits through different community members (Wang et al., 2017). Thus, CRT in the environment would respond to natural and man-made selective pressures as microbial species subjected to selective enrichments do under controlled conditions in the laboratory. This parallel between the rather recent rare biosphere and the well-established bioremediation literatures can be drawn by studies that simultaneously addressed prokaryotic community structures in the wild and in the corresponding enrichment cultures obtained after exposure to a stressor/carbon source. For example, Gomes et al. (2010) used a suite of molecular tools to examine Petroleum Hydrocarbon $(\mathrm{PH})$-degrading enrichment cultures from mangrove rhizospheres and sediments, and found that the bacterial populations, functional genes and plasmids responsible for $\mathrm{PH}$ degradation in the enriched cultures were below the detection limit in the source environment.

Besides CRT, some rare prokaryotic populations in the environment appear to remain active, or even increase their activity, while maintaining low or near-zero growth rates (Pester et al., 2010; Hausmann et al., 2016, 2019; Table 1). Using Stable Isotope Probing (SIP) of $16 \mathrm{~S}$ rRNA and dissimilatory (bi)sulfate reductase (dsrAB) genes, Pester et al. (2010) revealed that Desulfosporosinus spp., despite representing only $0.006 \%$ of the total microbial community, significantly contributed to sulfate reduction in peatland soils. Mesocosm experiments performed with periodic supplementation of individual fermentation products (formate, acetate, propionate, lactate or butyrate) in the presence or absence of sulfate further demonstrated that sulfate turnover in peatland soils was primarily mediated 
TABLE 1 | Selected microbial rare biosphere studies relevant for bioremediation.

\begin{tabular}{|c|c|c|c|c|}
\hline Sample type & Main methods & Relevance & Bioremediation potential & References \\
\hline Lakewater microcosms & $\begin{array}{l}\text { Serial dilution of microbial community from lake water to } \\
\text { simulate rare species loss; } \\
\text { Media with phenol or humic substances; } \\
\text { Diversity assessed by T-RFLP }{ }^{1} \text { of } 16 S \text { rRNA genes; } \\
\text { PCR-screening for the xilE gene. }\end{array}$ & $\begin{array}{l}\text { Microbial resistance to phenol and humic substances } \\
\text { decreases with rare species loss. }\end{array}$ & $\begin{array}{l}\text { Degradation of phenol } \\
\text { (associated with the presence of xilE genes, } \\
\text { for catechol 2,3 dioxygenase). }\end{array}$ & Szabó et al., 2007 \\
\hline $\begin{array}{l}\text { Mangrove sediment } \\
\text { and rhizospheres } \\
\text { spiked with petroleum }\end{array}$ & $\begin{array}{l}\text { Enrichment cultures assessed by PCR-DGGE, } \\
\text { hybridization and microarrays of petroleum } \\
\text { hydrocarbon (PH)-degrading genes and plasmids. }\end{array}$ & $\begin{array}{l}\text { Low abundance plasmids and functional genes } \\
\text { involved in } \mathrm{PH} \text { degradation become abundant in } \\
\text { petroleum contaminated soils. Rhizospheres of different } \\
\text { plant species possess their own unique community of } \\
\text { PH degraders. }\end{array}$ & $\begin{array}{l}\text { Degradation of } \mathrm{PHs} \text { by rare biosphere } \\
\text { members. }\end{array}$ & Gomes et al., 2010 \\
\hline Peatland soil & $16 \mathrm{~S}$ rRNA gene DNA-SIP, with and without sulfate. & $\begin{array}{l}\text { Desulfosporosinus ( } 0.006 \% \text { abundance) significantly } \\
\text { contributes to sulfate reduction. }\end{array}$ & $\begin{array}{l}\text { Sulfate reduction lowers methane emission } \\
\text { from peatland soils. }\end{array}$ & Pester et al., 2010 \\
\hline Marine & $\begin{array}{l}\text { Continuous seawater cultures exposed to different } \\
\text { salinity and DOC gradients; } \\
\text { PCR-DGGE and amplicon sequencing of } 16 \text { S rRNA } \\
\text { genes. }\end{array}$ & $\begin{array}{l}\text { Rare members of the community can grow abundant } \\
\text { after disturbance and contribute to overall community } \\
\text { stability. }\end{array}$ & $\begin{array}{l}\text { Resilience toward salinity and DOC } \\
\text { gradients. }\end{array}$ & $\begin{array}{l}\text { Sjöstedt et al., } \\
2012\end{array}$ \\
\hline $\begin{array}{l}\text { Soil microcosms } \\
\text { incubated with maize } \\
\text { litter as alkane source }\end{array}$ & $\begin{array}{l}\text { Enrichment of alkane-degrading bacteria by liquid } \\
\text { sub-cultivation; } \\
\text { Alkane degraders identified by alkB gene detection; } \\
\text { Community diversity assessed by T-RFLP of } 16 \mathrm{~S} \text { rRNA } \\
\text { genes. }\end{array}$ & $\begin{array}{l}\text { Description of previously unknown and rare alkane } \\
\text { degraders using complementary methodologies. }\end{array}$ & $\begin{array}{l}\text { Identification of a possible seed bank of } \\
\text { rare prokaryotes able to degrade alkanes. }\end{array}$ & Giebler et al., 2013 \\
\hline Marine & $\begin{array}{l}\text { DNA-SIP coupled with amplicon sequencing of } 16 S \\
\text { rRNA genes. }\end{array}$ & $\begin{array}{l}\text { Identification of disproportionately active degraders of } \\
\text { phenanthrene in the rare biosphere; } \\
\text { Identification of different rare biosphere groups tolerant } \\
\text { to PAHs in general. }\end{array}$ & Phenanthrene degradation. & Sauret et al., 2014 \\
\hline $\begin{array}{l}\text { Diesel-spiked soil } \\
\text { microcosm }\end{array}$ & Amplicon sequencing of $16 \mathrm{~S}$ rRNA genes. & $\begin{array}{l}\text { Identification of conditionally rare taxa that respond to } \\
\text { perturbance. }\end{array}$ & Hydrocarbon degradation. & Fuentes et al., 2016 \\
\hline PAH-contaminated soil & Microfluidic spread plating (High throughput cultivation). & $\begin{array}{l}\text { Methodology enables better coverage of rare } \\
\text { prokaryotes. Identification of a rare Blastococcus sp. } \\
\text { able to degrade fluoranthene. }\end{array}$ & $\begin{array}{l}\text { Fluoranthene degradation by a cultured } \\
\text { representative of the rare biosphere. }\end{array}$ & Jiang et al., 2016 \\
\hline Lakewater mesocosm & $\begin{array}{l}\text { HPLC; Amplicon sequencing of } 16 S \text { rRNA genes; Total } \\
\text { DNA sequencing. }\end{array}$ & $\begin{array}{l}\text { Rare biosphere members can respond to pollutants } \\
\text { that are rare or absent in the environment; The } \\
\text { response can be through growth or by HGT of plasmids } \\
\text { with the needed degradation pathways. }\end{array}$ & $\begin{array}{l}\text { 2,4-dichlorophenoxyacetic acid, } \\
\text { 4-nitrophenol, and caffeine degradation. }\end{array}$ & Wang et al., 2017 \\
\hline $\begin{array}{l}\text { Wood log in aquaria } \\
\text { with seawater }\end{array}$ & $\begin{array}{l}\text { Amplicon sequencing of } 16 \mathrm{~S} \text { rRNA genes; Sulfide } \\
\text { detection. }\end{array}$ & $\begin{array}{l}\text { "Ultra-rare" microbes can also respond to } \\
\text { environmental shifts; functional redundancy observed in } \\
\text { the rare biosphere. }\end{array}$ & $\begin{array}{l}\text { Community functions (e.g., sulfur cycling } \\
\text { pathways) are compromised under a } \\
\text { certain threshold of rare species removal. }\end{array}$ & $\begin{array}{l}\text { Kalenitchenko } \\
\text { et al., } 2018\end{array}$ \\
\hline Anoxic sludge & $\begin{array}{l}\text { Amplicon sequencing of } 16 \mathrm{~S} \text { rRNA genes; } \\
\text { Metatranscriptomics; } \\
\text { Sterols identification. }\end{array}$ & $\begin{array}{l}\text { Identification of new cholesterol degraders in the rare } \\
\text { biosphere (through the 2,3-seco pathway) }\end{array}$ & Anaerobic cholesterol degradation. & Wei et al., 2018 \\
\hline
\end{tabular}


by rare biosphere prokaryotes, involving both novel and already known sulfate reducing species (Hausmann et al., 2016). Among the latter, Desulfosporosinus spp. was considered not to grow abundant while maintaining a steadily active metabolism for 50 days, as indicated by ribosome/genome copy ratios estimated using qPCR (Hausmann et al., 2016). Finally, Hausmann et al. (2019) coupled genome-resolved metagenomics to metatranscriptomics to further explore the ecophysiology of sulfate reducing bacteria in the abovementioned mesocosms, revealing that the proposed novel species Candidatus Desulfosporosinus infrequens was able to concert near zero growth at low abundances with estimated high activity. This capacity was considered to result from over expression of genes for ribosome production, energy metabolism and response to stressors while displaying low expression of growth-associated genes (Hausmann et al., 2019).

This knowledge (at the genetic and functional levels) can prove useful in the industrial context because uncoupling bioproduct formation from cell growth (through proper exploitation of strains active at near zero growth states, for instance) is deemed relevant in process optimization (Ercan et al., 2015). For example, Lactic Acid Bacteria (LAB) in retentostat cultures remain viable for long periods of time, without biomass growth, after reaching the exponential growth phase (Ercan et al., 2013). This is typical in food fermentation processes, e.g., in cheese (Smit et al., 2005) and dry sausage (Hugas and Monfort, 1997) ripening, whereby $L A B$ can undergo long periods of very low nutrient availability while, regardless, playing a role in flavor development (Hugas and Monfort, 1997; see Ercan et al., 2013 for an extended discussion).

In fact, many biotechnology studies indeed focus on metabolic engineering of well-known strains to divert carbon flow toward specific bioproducts, instead of biomass (Papagianni, 2012). Likewise, synthetic biology approaches hold promise in the development of engineered strains displaying increased tolerance to a range of stressors, thereby facilitating bioproduct formation (Jia et al., 2014). Ecologists interested in the prokaryotic rare biosphere aim to understand how prokaryotes remain viable in a non-dormant state for long periods of time (e.g., Hausmann et al., 2019), whereas biotechnology-oriented research aims at optimizing biological processes. The interface between the two research fields lies in the study of metabolic trade-offs dictating energy allocation to cell growth and/or activity, and the environmental variables/laboratory conditions that are relevant to fine-tune cellular metabolism.

\section{THE PROKARYOTIC RARE BIOSPHERE RESPONDS TO POLLUTANTS: POTENTIAL FOR BIOREMEDIATION}

Well known functions involved in environmental recovery from pollutants can also be stored in the prokaryotic seed bank, until they are necessary, as suggested by a lake water mesocosms experiment (Wang et al., 2017) testing the effect of different organic compounds (2,4-dichlorophenoxyacetic acid, a herbicide, 1,3,7-trimethyluric acid, caffeine and 4-nitrophenol, 


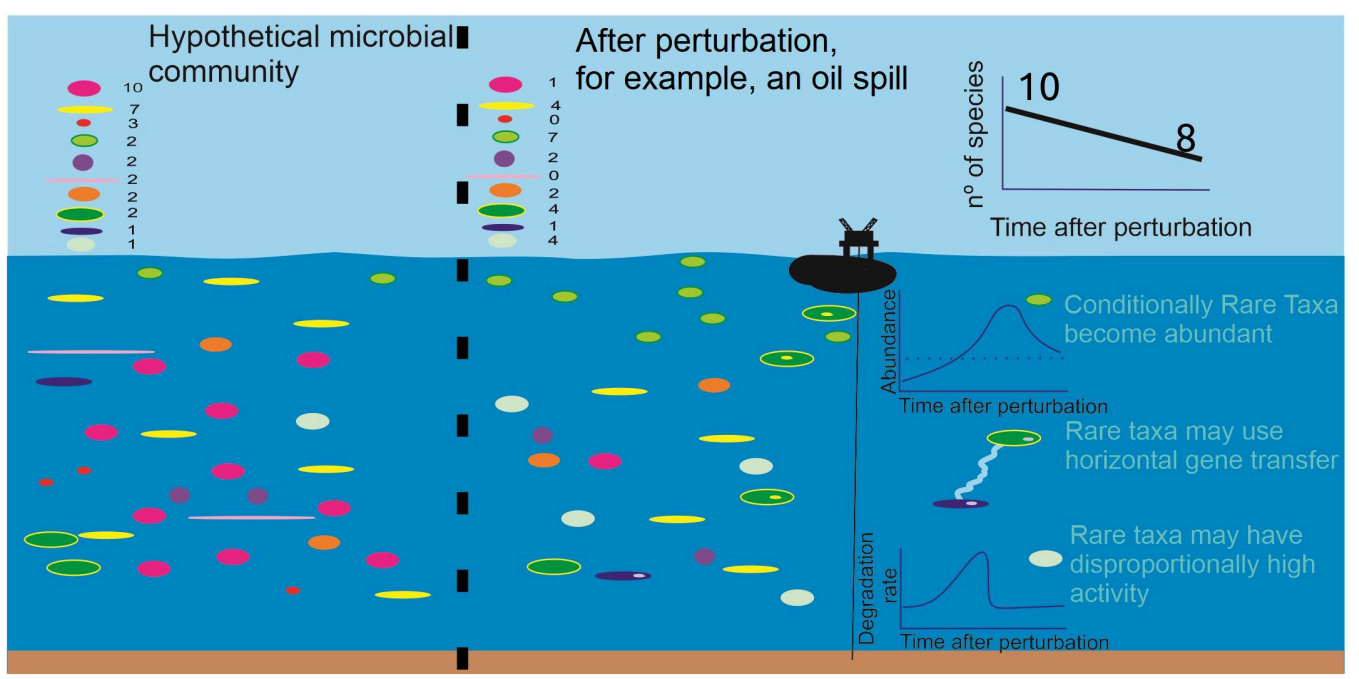

FIGURE 1 | Hypothetical, oversimplified marine microbial community composed of 10 different species, originally with 32 total individuals (a proxy for e.g., $3.2 \times 10^{6}$ cells. $\mathrm{mL}^{-1}$ ). Most of the species are rare and after a perturbation, such as an oil spill exemplified in the picture, it is expected that the overall diversity decreases, and that some rare species become abundant, some tolerate the perturbation and others do not tolerate the perturbation, entering local extinction. We summarize how the prokaryotic rare biosphere is thought to respond to such perturbations. Conditionally rare taxa can grow abundantly and degrade the pollutant(s) as part of their normal metabolism. When the stressor is completely degraded, they may go back to low abundance. Rare taxa, in these conditions, may also transfer functional genes to other more abundant bacteria, helping the community to cope with the perturbation. Finally, it is also thought that some rare taxa may display high activity, relative to their abundance, for the metabolism of specific compounds; they could possibly show a high degradation rate while the stressor is present, and thereafter return to low activity.

a pesticide) on prokaryotic community composition. Even though these compounds were not detected in the lake, rare bacteria had the genetic machinery to respond to the stressors (Table 1). Further analysis showed that several rare taxa were enriched after addition of 2,4-dichlorophenoxyacetic acid, namely Burkholderia, Sphingopyxis, and Variovorax spp. The genetic pathways for the degradation of the stressors were below the detection limits prior to incubation but were afterward identified, with variations across replicates (Wang et al., 2017; Table 1). Further, the catabolism of cholesterol was found to be mediated through the 2,3-seco pathway by rare bacteria from the denitrifying sludge of a wastewater treatment plant (Wei et al., 2018; Table 1). Finally, community-level resistance and degradation of phenols, which are toxic compounds often released into the environment due to industrial activities (Duan et al., 2018), has been as well related with the prokaryotic rare biosphere (Szabó et al., 2007; Table 1).

Although bioremediation procedures already exist for the treatment of oil spills, improvements are needed to minimize environmental consequences of large spill incidents (Ron and Rosenberg, 2014). It is now known that the rare prokaryotic biosphere contributes to the degradation of Polycyclic Aromatic Hydrocarbons (PAHs) in natural environments (Table 1). For instance, Sauret et al. (2014) described the in situ enrichment of rare biosphere populations after coastal seawater samples had been amended with phenanthrene, with both well-known (e.g., Cycloclasticus spp.) and then-unrecognized (e.g., Oceanibaculum and Sneathiella spp.) phenanthrenedegrading populations observed to behave as CRT under the experimental circumstances. Currently, the metabolism of known
PAH-degrading bacteria is mostly studied in the laboratory and application of this knowledge to mitigate environmental pollution should be supported by in situ based studies (Sauret et al., 2014). In soil, while testing bioremediation and bioaugmentation strategies for oil spills, it was reported that rare microbes mediated the response to drastic stress (high concentrations of oil), and that bioaugmentation introduced novel CRT into the system (Fuentes et al., 2016). In another study, Giebler et al. (2013) identified a possible seed bank of rare prokaryotes, originated from pristine soils, with the ability to degrade alkanes. Finally, manipulative experiments with Arctic and Antarctic microplankton communities showed that the addition of hydrophobic, anthropogenic dissolved organic carbon reduced overall microbial diversity and that the degradation response was mediated by rare prokaryotes (Cerro-Gálvez et al., 2019).

Altogether, recent research suggests that low abundance prokaryotes confer resilience to natural microbial communities upon exposure to pollutants. The described responses, however, most often involved the increase in abundance of CRT present in the samples, analogously to enrichment culture experiments performed in the laboratory.

\section{GENETIC DIVERSITY AND NOVELTY - BIOPROSPECTING POTENTIAL}

The pool of microorganisms currently uncultivatable in the laboratory ("microbial dark matter"), encompasses much phylogenetic novelty, including phylotypes displaying an 
uncommon biology with alternative metabolic pathways such as different genetic codes and unusual ribosomal composition, reflecting genes and functions that are yet to be discovered (Wu et al., 2011; Lynch et al., 2012; Rinke et al., 2013; Brown et al., 2015; Solden et al., 2016). The prokaryotic rare biosphere may include groups that are phylogenetically close or distant from abundant taxa (Elshahed et al., 2008), also identified among rare eukaryotes (Logares et al., 2014; Debroas et al., 2015). Phylogenetically distant prokaryotic taxa were found to contribute more to community turnover after new perturbations (Coveley et al., 2015), suggesting phylogenetic diversity in the response process. In sulfur springs, an approach combining high throughput and Sanger sequencing technologies revealed that several rare, unclassified lineages did represent novel phyla and classes (Youssef et al., 2012). Similar findings were reported for Arctic tundra soils, where a component of the rare biosphere included previously unknown taxa (Lynch et al., 2012).

Many unknown functional genes from the rare biosphere might yet be inaccessible, even with the current power of high throughput sequencing techniques (Ekkers et al., 2012; Lynch et al., 2012; Crespo et al., 2016). Moreover, the fact that a large portion of this community is hitherto uncultivatable remains one major hindrance in bioprospecting for novel activities within the unknown component of the rare biosphere. To effectively exploit such a vast reservoir of prokaryotic diversity, blending of multiple, advanced technologies is needed to further our knowledge of the prokaryotic rare biosphere beyond mere rRNA gene sequencing.

Continued investment in total community, metagenomic DNA sequencing coupled to the subsequent binning of MAGs from diverse environments is expected to substantially improve knowledge of the coding potential (Brown et al., 2015) and bioremediation and biogeochemical cycling (Hausmann et al., 2019) functions within the rare biosphere in the following years. However, there is currently a gap between the number of "new" proteins predicted from genome annotations and those which are fully characterized (Galperin and Koonin, 2010; Bastard et al., 2014). Improving genome annotations through experimental characterization of novel proteins will be paramount to increase our knowledge of the functional attributes of rare prokaryotes. Alternative cultivation methodologies, especially when complemented by genome sequencing ("culturomics"), can increase our ability to document the diversity and function of low-abundance prokaryotes and eukaryotes, including fungi (Lagier et al., 2012).

Comprehensive culturing, either involving taxon-specific or oligotrophic medium compositions, often permits access to diverse, rare prokaryotes not depicted by molecular techniques alone (Hardoim et al., 2014; Zehavi et al., 2018; Karimi et al., 2019; Rego et al., 2019) while enabling access to their metabolism and bioactivities. For instance, broad-spectrum antimicrobial activities have been reported for freshwater sponge-associated Pseudomonas spp. (Keller-Costa et al., 2014) which did not rank among the dominant bacteria in the system (Costa et al., 2013). Currently, access to much novel secondary metabolism among prokaryotes is being achieved by combining genomics, computational biology and analytical chemistry to the study of rare or "hard-to-culture" bacteria (Helfrich et al., 2019; Silva et al., 2019). Finally, the use microfluidics in high-throughput cultivation enables the screening for bioremediation functions among rare taxa in a complex community (Jiang et al., 2016; Table 1).

\section{CONCLUDING REMARKS}

A significant component of the known and unknown prokaryotic diversity exists at low abundance in the environment. This mini review bridged recently developed concepts regarding the ecophysiology of low abundance prokaryotes with current knowledge from biotechnology. Many CRT have been reported to respond to pollutants in the environment, whereby the active response was not necessarily performed by well-established strains already in use for bioremediation processes. Furthermore, most low abundance prokaryotes remain uncultured and consequently understudied, being an important source for bioprospecting new functions, as well as gene and protein microheterogeneities underlying the expression of already known functions. Although very useful in biodiscovery, metagenomicscentered methods alone will not suffice to truly illuminate the breadth of potential new functions or variations of known functions hidden in the prokaryotic rare biosphere, neither improve their use in applied biotechnology. To this end, coupling culturomics to DNA mutagenesis research will be ultimately necessary to assign novel functions to the wealth of so-far hypothetical proteins which still dominate genome annotations of even the most well-known and studied prokaryotes. Moreover, recent advances in genome editing technologies and synthetic biology hold much promise in leveraging our capacity to engineer e.g., pollutant-removing (Dvořák et al., 2017), drug-producing (Wang et al., 2019) and stress-tolerant (Jia et al., 2014) bacteria, thus facilitating our ability to harness the metabolism of both culturable and thus far unculturable low abundance prokaryotes in biotechnology.

\section{AUTHOR CONTRIBUTIONS}

FP, CM, and RC conceptualized the manuscript. FP wrote the main manuscript. $\mathrm{CM}$ and $\mathrm{RC}$ reviewed and improved the manuscript.

\section{FUNDING}

The Portuguese Science and Technology Foundation (FCT) funded this study through a grant to CM (PTDC/CTAAMB/30997/2017). Further support was provided to the Institute of Bioengineering and Biosciences by "Programa Operacional Regional de Lisboa” (Project No. 007317). This research was also partially supported by the Strategic Funding UIDB/04423/2020, UIDP/04423/2020, and UIDB/04565/2020 through national funds provided by the FCT - Foundation for Science and Technology and European Regional Development Fund (ERDF), in the framework of the "PT2020" program. 


\section{REFERENCES}

Bastard, K., Smith, A. A. T., Vergne-Vaxelaire, C., Perret, A., Zaparucha, A., De Melo-Minardi, R., et al. (2014). Revealing the hidden functional diversity of an enzyme family. Nat. Chem. Biol. 10, 42-49. doi: 10.1038/nchembio.1387

Bowen, J. L., Morrison, H. G., Hobbie, J. E., and Sogin, M. L. (2012). Salt marsh sediment diversity: a test of the variability of the rare biosphere among environmental replicates. ISME J. 6, 2014-2023. doi: 10.1038/ismej.2012.47

Brown, C. T., Hug, L. A., Thomas, B. C., Sharon, I., Castelle, C. J., Singh, A., et al. (2015). Unusual biology across a group comprising more than $15 \%$ of domain Bacteria. Nature 523, 208-211. doi: 10.1038/nature14486

Campbell, B. J., Yu, L., Heidelberg, J. F., and Kirchman, D. L. (2011). Activity of abundant and rare bacteria in a coastal ocean. Proc. Natl. Acad. Sci. U.S.A. 108, 12776-12781. doi: 10.1073/pnas.1101405108

Caron, D., and Countway, P. (2009). Hypotheses on the role of the protistan rare biosphere in a changing world. Aquat. Microb. Ecol. 57, 227-238. doi: 10.3354/ame01352

Cerro-Gálvez, E., Casal, P., Lundin, D., Piña, B., Pinhassi, J., Dachs, J., et al. (2019). Microbial responses to anthropogenic dissolved organic carbon in the Arctic and Antarctic coastal seawaters. Environ. Microbiol. 21, 1466-1481. doi: 10.1111/1462-2920.14580

Costa, R., Keller-Costa, T., Gomes, N. C. M., da Rocha, U. N., van Overbeek, L., and van Elsas, J. D. (2013). Evidence for selective bacterial community structuring in the freshwater sponge ephydatia fluviatilis. Microb. Ecol. 65, 232-244. doi: 10.1007/s00248-012-0102-2

Coveley, S., Elshahed, M. S., and Youssef, N. H. (2015). Response of the rare biosphere to environmental stressors in a highly diverse ecosystem (Zodletone spring. OK, USA). PeerJ. 3, e1182. doi: 10.7717/peerj.1182

Crespo, B. G., Wallhead, P. J., Logares, R., and Pedrós-Alió, C. (2016). Probing the rare biosphere of the north-west mediterranean sea: an experiment with high sequencing effort. PLoS One 11:e0159195. doi: 10.1371/journal.pone.0159195

Debroas, D., Hugoni, M., and Domaizon, I. (2015). Evidence for an active rare biosphere within freshwater protists community. Mol. Ecol. 24, 1236-1247. doi: $10.1111 / \mathrm{mec} .13116$

Duan, W., Meng, F., Cui, H., Lin, Y., Wang, G., and Wu, J. (2018). Ecotoxicity of phenol and cresols to aquatic organisms: a review. Ecotoxicol. Environ. Saf. 157, 441-456. doi: 10.1016/j.ecoenv.2018.03.089

Dvořák, P., Nikel, P. I., Damborský, J., and de Lorenzo, V. (2017). Bioremediation 3.0: engineering pollutant-removing bacteria in the times of systemic biology. Biotechnol. Adv. 35, 845-866. doi: 10.1016/j.biotechadv.2017.08.001

Ekkers, D. M., Cretoiu, M. S., Kielak, A. M., and Van Elsas, J. D. (2012). The great screen anomaly-a new frontier in product discovery through functional metagenomics. Appl. Microbiol. Biotechnol. 93, 1005-1020. doi: 10.1007/ s00253-011-3804-3

Elshahed, M. S., Youssef, N. H., Spain, A. M., Sheik, C., Najar, F. Z., Sukharnikov, L. O., et al. (2008). Novelty and uniqueness patterns of rare members of the soil biosphere. Appl. Environ. Microbiol. 74, 5422-5428. doi: 10.1128/AEM.004 10-08

Ercan, O., Bisschops, M. M. M., Overkamp, W., Jørgensen, T. R., Ram, A. F., Smid, E. J., et al. (2015). Physiological and transcriptional responses of different industrial microbes at near-zero specific growth rates. Appl. Environ. Microbiol. 81, 5662-5670. doi: 10.1128/AEM.00944-15

Ercan, O., Smid, E. J., and Kleerebezem, M. (2013). Quantitative physiology of Lactococcus lactis at extreme low-growth rates. Environ. Microbiol. 15, 23192332. doi: 10.1111/1462-2920.12104

Fuentes, S., Barra, B., Caporaso, J. G., and Seeger, M. (2016). From rare to dominant: a fine-tuned soil bacterial bloom during petroleum hydrocarbon bioremediation. Appl. Environ. Microbiol. 82, 888-896. doi: 10.1128/AEM. 02625-15

Fuhrman, J. A. (2009). Microbial community structure and its functional implications. Nature 459, 193-199. doi: 10.1038/nature08058

Galand, P. E., Casamayor, E. O., Kirchman, D. L., and Lovejoy, C. (2009). Ecology of the rare microbial biosphere of the Arctic Ocean. Proc. Natl. Acad. Sci. U.S.A. 106, 22427-22432. doi: 10.1073/pnas.0908284106

Galperin, M. Y., and Koonin, E. V. (2010). From complete genome sequence to "complete" understanding? Trends Biotechnol. 28, 398-406. doi: 10.1016/j. tibtech.2010.05.006
Giebler, J., Wick, L. Y., Chatzinotas, A., and Harms, H. (2013). Alkane-degrading bacteria at the soil-litter interface: comparing isolates with T-RFLP-based community profiles. FEMS Microbiol. Ecol. 86, 45-58. doi: 10.1111/1574-6941. 12097

Gobet, A., Böer, S. I., Huse, S. M., van Beusekom, J. E. E., Quince, C., Sogin, M. L., et al. (2012). Diversity and dynamics of rare and of resident bacterial populations in coastal sands. ISME J. 6, 542-553. doi: 10.1038/ismej.201 1.132

Gomes, N. C. M., Flocco, C. G., Costa, R., Junca, H., Vilchez, R., Pieper, D. H., et al. (2010). Mangrove microniches determine the structural and functional diversity of enriched petroleum hydrocarbon-degrading consortia. FEMS Microbiol. Ecol. 74, 276-290. doi: 10.1111/j.1574-6941.2010.00962.x

Hardoim, C. C. P., Cardinale, M., Cúcio, A. C. B., Esteves, A. I. S., Berg, G., Xavier, J. R., et al. (2014). Effects of sample handling and cultivation bias on the specificity of bacterial communities in keratose marine sponges. Front. Microbiol. 5:611. doi: 10.3389/fmicb.2014.00611

Hausmann, B., Knorr, K.-H. H., Schreck, K., Tringe, S. G., Glavina, del Rio, T., et al. (2016). Consortia of low-abundance bacteria drive sulfate reduction-dependent degradation of fermentation products in peat soil microcosms. ISME J. 10, 2365-2375. doi: 10.1038/ismej.2016.42

Hausmann, B., Pelikan, C., Rattei, T., Loy, A., and Pester, M. (2019). Longterm transcriptional activity at zero growth of a cosmopolitan rare biosphere member. MBio 10, 1-16. doi: 10.1128/mBio.02189-18

Helfrich, E. J. N., Ueoka, R., Dolev, A., Rust, M., Meoded, R. A., Bhushan, A., et al. (2019). Automated structure prediction of trans-acyltransferase polyketide synthase products. Nat. Chem. Biol. 15, 813-821. doi: 10.1038/s41589-0190313-7

Hugas, M., and Monfort, J. M. (1997). Bacterial starter cultures for meat fermentation. Food Chem. 59, 547-554. doi: 10.1016/S0308-8146(97)00005-8

Hugoni, M., Taib, N., Debroas, D., Domaizon, I., Jouan Dufournel, I., Bronner, G., et al. (2013). Structure of the rare archaeal biosphere and seasonal dynamics of active ecotypes in surface coastal waters. Proc. Natl. Acad. Sci. U.S.A. 110, 6004-6009. doi: 10.1073/pnas.1216863110

Jia, H., Fan, Y., Feng, X., and Li, C. (2014). Enhancing stress-resistance for efficient microbial biotransformations by synthetic biology. Front. Bioeng. Biotechnol. 2:44. doi: $10.3389 /$ fbioe.2014.00044

Jia, X., Dini-Andreote, F., and Salles, J. F. (2018). Community assembly processes of the microbial rare biosphere. Trends Microbiol. 26, 738-747. doi: 10.1016/j. tim.2018.02.011

Jiang, C.-Y., Dong, L., Zhao, J.-K., Hu, X., Shen, C., Qiao, Y., et al. (2016). Highthroughput single-cell cultivation on microfluidic streak plates. Appl. Environ. Microbiol. 82, 2210-2218. doi: 10.1128/AEM.03588-15

Jones, S. E., and Lennon, J. T. (2010). Dormancy contributes to the maintenance of microbial diversity. Proc. Natl. Acad. Sci. U.S.A. 107, 5881-5886. doi: 10.1073/ pnas.0912765107

Jousset, A., Bienhold, C., Chatzinotas, A., Gallien, L., Gobet, A., Kurm, V., et al. (2017). Where less may be more: how the rare biosphere pulls ecosystems strings. ISME J. 11, 853-862. doi: 10.1038/ismej.2016.174

Kalenitchenko, D., Le Bris, N., Peru, E., and Galand, P. E. (2018). Ultrarare marine microbes contribute to key sulphur-related ecosystem functions. Mol. Ecol. 27, 1494-1504. doi: 10.1111/mec.14513

Karimi, E., Keller-Costa, T., Slaby, B. M., Cox, C. J., da Rocha, U. N., Hentschel, U., et al. (2019). Genomic blueprints of sponge-prokaryote symbiosis are shared by low abundant and cultivatable Alphaproteobacteria. Sci. Rep. 9, 1-15. doi: 10.1038/s41598-019-38737-x

Keller-Costa, T., Jousset, A., Van Overbeek, L., Van Elsas, J. D., and Costa, R. (2014). The freshwater sponge Ephydatia fluviatilis harbours diverse Pseudomonas species (Gammaproteobacteria, Pseudomonadales) with broadspectrum antimicrobial activity. PLoS One 9:e88429. doi: 10.1371/journal.pone. 0088429

Kirchman, D. L., Cottrell, M. T., and Lovejoy, C. (2010). The structure of bacterial communities in the western Arctic Ocean as revealed by pyrosequencing of $16 \mathrm{~S}$ rRNA genes. Environ. Microbiol. 12, 1132-1143. doi: 10.1111/j.1462-2920.2010. 02154.x

Lagier, J. C., Armougom, F., Million, M., Hugon, P., Pagnier, I., Robert, C., et al. (2012). Microbial culturomics: paradigm shift in the human gut microbiome study. Clin. Microbiol. Infect. 18, 1185-1193. doi: 10.1111/1469-0691.12023 
Liu, L., Yang, J., Yu, Z., and Wilkinson, D. M. (2015). The biogeography of abundant and rare bacterioplankton in the lakes and reservoirs of China. ISME J. 9, 2068-2077. doi: 10.1038/ismej.2015.29

Lloyd, K. G., Steen, A. D., Ladau, J., Yin, J., and Crosby, L. (2018). Phylogenetically novel uncultured microbial cells dominate earth microbiomes. mSystems 3, 1-12. doi: 10.1128/mSystems.00055- 18

Logares, R., Audic, S., Bass, D., Bittner, L., Boutte, C., Christen, R., et al. (2014). Patterns of rare and abundant marine microbial eukaryotes. Curr. Biol. 24, 813-821. doi: 10.1016/j.cub.2014.02.050

Logares, R., Lindström, E. S., Langenheder, S., Logue, J. B., Paterson, H., LaybournParry, J., et al. (2013). Biogeography of bacterial communities exposed to progressive long-term environmental change. ISME J. 7, 937-948. doi: 10.1038/ ismej. 2012.168

Logares, R., Mangot, J. F., and Massana, R. (2015). Rarity in aquatic microbes: placing protists on the map. Res. Microbiol. 166, 831-841. doi: 10.1016/j.resmic. 2015.09.009

Lynch, M. D. J., Bartram, A. K., and Neufeld, J. D. (2012). Targeted recovery of novel phylogenetic diversity from next-generation sequence data. ISME J. 6, 2067-2077. doi: 10.1038/ismej.2012.50

Lynch, M. D. J., and Neufeld, J. D. (2015). Ecology and exploration of the rare biosphere. Nat. Rev. Microbiol. 13, 217-229. doi: 10.1038/nrmicro3400

Murdock, S. A., and Juniper, S. K. (2019). Hydrothermal vent protistan distribution along the Mariana arc suggests vent endemics may be rare and novel. Environ. Microbiol. 21, 3796-3815. doi: 10.1111/1462-2920.14729

Neufeld, J. D., Li, J., and Mohn, W. W. (2008). Scratching the surface of the rare biosphere with ribosomal sequence tag primers. FEMS Microbiol. Lett. 283, 146-153. doi: 10.1111/j.1574-6968.2008.01124.x

Papagianni, M. (2012). Recent advances in engineering the central carbon metabolism of industrially important bacteria. Microb. Cell Fact. 11, 1-13. doi: 10.1186/1475-2859-11-50

Pedrós-Alió, C. (2006). Marine microbial diversity: can it be determined? Trends Microbiol. 14, 257-263. doi: 10.1016/j.tim.2006.04.007

Pedrós-Alió, C. (2012). The rare bacterial biosphere. Ann. Rev. Mar. Sci. 4, 449-466. doi: 10.1146/annurev-marine-120710100948

Pester, M., Bittner, N., Deevong, P., Wagner, M., and Loy, A. (2010). A 'rare biosphere' microorganism contributes to sulfate reduction in a peatland. ISME J. 4, 1591-1602. doi: 10.1038/ismej.2010.75

Ramond, J.-B., Makhalanyane, T. P., Tuffin, M. I., and Cowan, D. A. (2015). Normalization of environmental metagenomic DNA enhances the discovery of under-represented microbial community members. Lett. Appl. Microbiol. 60, 359-366. doi: 10.1111/lam.12380

Rego, A., Raio, F., Martins, T. P., Ribeiro, H., Sousa, A. G. G., Séneca, J., et al. (2019). Actinobacteria and cyanobacteria diversity in terrestrial antarctic microenvironments evaluated by culture-dependent and independent methods. Front. Microbiol. 10:1018. doi: 10.3389/fmicb.2019.01018

Rinke, C., Schwientek, P., Sczyrba, A., Ivanova, N. N., Anderson, I. J., Cheng, J.F. F., et al. (2013). Insights into the phylogeny and coding potential of microbial dark matter. Nature 499, 431-437. doi: 10.1038/nature12352

Ron, E. Z., and Rosenberg, E. (2014). Enhanced bioremediation of oil spills in the sea. Curr. Opin. Biotechnol 27, 191-194. doi: 10.1016/j.copbio.2014.02.004

Sauret, C., Séverin, T., Vétion, G., Guigue, C., Goutx, M., Pujo-Pay, M., et al. (2014). 'Rare biosphere' bacteria as key phenanthrene degraders in coastal seawaters. Environ. Pollut. 194, 246-253. doi: 10.1016/j.envpol.2014.07.024

Shade, A., Hogan, C. S., Klimowicz, A. K., Linske, M., McManus, P. S., and Handelsman, J. (2012). Culturing captures members of the soil rare biosphere. Environ. Microbiol. 14, 2247-2252. doi: 10.1111/j.1462-2920.2012.02 817.x

Shade, A., Jones, S. E., Caporaso, J. G., Handelsman, J., Knight, R., Fierer, N., et al. (2014). Conditionally rare taxa disproportionately contribute to temporal changes in microbial diversity. MBio 5, 1-9. doi: 10.1128/mBio.0137114

Silva, S. G., Blom, J., Keller-Costa, T., and Costa, R. (2019). Comparative genomics reveals complex natural product biosynthesis capacities and carbon metabolism across host-associated and free-living Aquimarina (Bacteroidetes, Flavobacteriaceae) species. Environ. Microbiol 21, 4002-4019. doi: $10.1111 / 1462-2920.14747$
Sjöstedt, J., Koch-Schmidt, P., Pontarp, M., Canbäck, B., Tunlid, A., Lundberg, P., et al. (2012). Recruitment of members from the rare biosphere of marine bacterioplankton communities after an environmental disturbance. Appl. Environ. Microbiol. 78, 1361-1369. doi: 10.1128/AEM.05542-11

Smit, G., Smit, B. A., and Engels, W. J. M. (2005). Flavour formation by lactic acid bacteria and biochemical flavour profiling of cheese products. FEMS Microbiol. Rev. 29, 591-610. doi: 10.1016/j.femsre.2005.04.002

Sogin, M. L., Morrison, H. G., Huber, J. A., Welch, D. M., Huse, S. M., Neal, P. R., et al. (2006). Microbial diversity in the deep sea and the underexplored "rare biosphere.”. Proc. Natl. Acad. Sci. U.S.A. 103, 12115-12120. doi: 10.1073/pnas. 0605127103

Solden, L., Lloyd, K., and Wrighton, K. (2016). The bright side of microbial dark matter: lessons learned from the uncultivated majority. Curr. Opin. Microbiol. 31, 217-226. doi: 10.1016/j.mib.2016.04.020

Szabó, K. É, Itor, P. O. B., Bertilsson, S., Tranvik, L., and Eiler, A. (2007). Importance of rare and abundant populations for the structure and functional potential of freshwater bacterial communities. Aquat. Microb. Ecol. 47, 1-10. doi: 10.3354/ame047001

Vergin, K., Done, B., Carlson, C., and Giovannoni, S. (2013). Spatiotemporal distributions of rare bacterioplankton populations indicate adaptive strategies in the oligotrophic ocean. Aquat. Microb. Ecol. 71, 1-13. doi: 10.3354/ame01661

Wang, G., Zhao, Z., Ke, J., Engel, Y., Shi, Y.-M., Robinson, D., et al. (2019). CRAGE enables rapid activation of biosynthetic gene clusters in undomesticated bacteria. Nat. Microbiol. 4, 2498-2510. doi: 10.1038/s41564-019-05738

Wang, Y., Hatt, J. K., Tsementzi, D., Rodriguez-R, L. M., Ruiz-Pérez, C. A., Weigand, M. R., et al. (2017). Quantifying the importance of the rare biosphere for microbial community response to organic pollutants in a freshwater ecosystem. Appl. Environ. Microbiol. 83:e03321-16. doi: 10.1128/AEM.033 21-16

Wei, S. T.-S., Wu, Y.-W., Lee, T.-H., Huang, Y.-S., Yang, C.-Y., Chen, Y.-L., et al. (2018). Microbial functional responses to cholesterol catabolism in denitrifying sludge. $m$ Systems 3, 1-19. doi: 10.1128/msystems.00113-18

Weisse, T. (2014). Ciliates and the rare biosphere-community ecology and population dynamics. J. Eukaryot. Microbiol. 61, 419-433. doi: 10.1111/jeu. 12123

Wu, D., Wu, M., Halpern, A., Rusch, D. B., Yooseph, S., Frazier, M., et al. (2011). Stalking the fourth domain in metagenomic data: searching for, discovering, and interpreting novel, deep branches in marker gene phylogenetic trees. PLoS One 6:e18011. doi: 10.1371/journal.pone.0018011

Youssef, N., Steidley, B. L., and Elshahed, M. S. (2012). Novel high-rank phylogenetic lineages within a sulfur spring (Zodletone Spring, Oklahoma), revealed using a combined pyrosequencing-sanger approach. Appl. Environ. Microbiol. 78, 2677-2688. doi: 10.1128/AEM.00002-12

Youssef, N. H., Couger, M. B., and Elshahed, M. S. (2010). Fine-scale bacterial beta diversity within a complex ecosystem (Zodletone Spring, OK, USA): the role of the rare biosphere. PLoS One 5:e12414. doi: 10.1371/journal.pone.0012414

Zehavi, T., Probst, M., and Mizrahi, I. (2018). Insights into culturomics of the rumen microbiome. Front. Microbiol. 9:1999. doi: 10.3389/fmicb.2018.01999

Zhang, Q. G., Buckling, A., and Godfray, H. C. J. (2009). Quantifying the relative importance of niches and neutrality for coexistence in a model microbial system. Funct. Ecol. 23, 1139-1147. doi: 10.1111/j.1365-2435.2009.01579.x

Ziegler, M., Eguíluz, V. M., Duarte, C. M., and Voolstra, C. R. (2018). Rare symbionts may contribute to the resilience of coral-algal assemblages. ISME J. 12, 161-172. doi: 10.1038/ismej.2017.151

Conflict of Interest: The authors declare that the research was conducted in the absence of any commercial or financial relationships that could be construed as a potential conflict of interest.

Copyright (c) 2020 Pascoal, Magalhães and Costa. This is an open-access article distributed under the terms of the Creative Commons Attribution License (CC BY). The use, distribution or reproduction in other forums is permitted, provided the original author(s) and the copyright owner(s) are credited and that the original publication in this journal is cited, in accordance with accepted academic practice. No use, distribution or reproduction is permitted which does not comply with these terms. 